\title{
Dimensions of Context Affecting User Experience in Mobile Work
}

\author{
Heli Wigelius and Heli Väätäjä \\ Tampere University of Technology, Human-Centered Technology \\ P.O. Box 589, 33101 Tampere, Finland \\ \{heli.wigelius, heli.vaataja\}atut.fi
}

\begin{abstract}
Understanding the contextual factors affecting user experience is essential in designing and evaluating mobile systems for mobile work. The aim of this paper is to explore these contextual factors through three case studies: of safety observation at construction sites, passenger transportation with taxis, and mobile news journalism. For each case study we describe the nature of the mobile work and present our findings on the contextual factors that were found to affect the user experience. Based on the results, we present and discuss five dimensions of mobile work context affecting user experience: 1) social, 2) spatial, 3) temporal, 4) infrastructural, and 5) task context. Compared to earlier frameworks of context for mobile work, the social context as well as the infrastructural context was emphasized in our findings. The presented framework elaborates the dimensions of context affecting user experience of mobile systems and services in mobile work in particular. The framework is also applicable for mobile consumer systems and services.
\end{abstract}

Keywords: context, mobile work, user experience, mobile systems.

\section{Introduction}

The importance of understanding context has been highlighted in many studies in the field of Human-Computer Interaction (HCI) [1], [2], [3], [4]. When a new technology, for example a mobile system, becomes a part of traditional work tasks it is essential to ensure that work activities are appropriately supported [5]. Furthermore, several user experience frameworks and definitions mention context as one of the components affecting user experience [6], [7]. [8]. If the context has not been identified and understood, the use of the mobile systems may fail or the user experience may suffer. However, empirical research on user experience has mainly concentrated on consumer products and services, with only a few focusing on the mobile work context [4], [9], [10], [11], [12].

In this paper, we present our findings from three exploratory case studies on the contextual factors affecting user experience in mobile work. We focused on mobile systems that support the work of mobile workers. The case studies were of safety observation at construction sites, passenger transportation, and mobile news journalism. The data was gathered via observations and interviews. Through these case studies, we examine the nature of mobile work and present examples of identified contextual 
factors affecting the user experience. Based on our findings we then present an elaborated framework for the dimensions of these contextual factors.

The rest of the paper is structured as follows. First, we review earlier research on context from ubiquitous computing, user experience and mobile work. We continue by describing the research methods and by presenting the results regarding the contextual factors found to affect user experience in the cases studied. We then discuss and summarize the results by presenting a framework for context in mobile work and describe the identified dimensions.

\section{Related Work}

The concept of context has been discussed extensively in the areas of ComputerSupported Cooperative Work (CSCW) [13], ubiquitous and context-aware computing [14], [15], [16], and user experience [17] as well as in mobile work [4], [18]. A number of attempts have been made to define context [14], including a standardized definition for the context of use [19]. As Dey states, context is a word that is understood easily but is hard to define clearly [15]. One of the most recent definitions for context is proposed by Bradley and Dunlop [14] for context-aware computing. They propose a dynamic model of context based on the definitions taken from linguistics, computer science and psychology. According to them, the user's contextual world comprises the task, physical, social, temporal, and cognitive context.

Context is also an essential part of the interaction oriented frameworks of user experience. In these frameworks user experience is defined as a consequence of the user's interaction with the product, system or service, which is affected by characteristics of the user and the system as well as by contextual factors [6], [7], [8]. In the case of mobile browsing, Roto [17] identifies four dimensions of mobile context affecting the user experience, namely physical context, social context, temporal context and task context. Roto [17] describes the physical context as being any circumstances that physically affect the use of the mobile browser, such as weather conditions, light, crowds, and noise. Social context refers to the expectations of other people in regard to the user in the present context, such as in a meeting. Temporal context refers to the time period that the user dedicates to the system, but limited by the restrictions of the context, such as a commuter interrupting their usage as they get on and off a bus. Roto [17] uses the term task context to refer to the user's higher-level goal, where mobile browsing is merely one task in accomplishing the goal. She gives the example where a user is going home by a bus and checking the timetables with the mobile browser, but their high level goal is to get home.

Several definitions have been presented for both mobile context [20], [21] and mobile work context [4], [18], as shown in Table 1. For example, the definition of mobile work context given by Zheng and Yuan [4] consists of mobile context (where and when), mobile workers (who), mobile technologies (how), and mobile tasks (what); a definition also supported by other literature (See Table 1). Furthermore, Turel [22] includes users' motivation in his definition of context, which is mentioned as one of the user characteristics in frameworks for user experience [8], [17].

In our study we follow the approach of the interaction oriented definitions of user experience, where user, system and context are the basic elements affecting the user 
Table 1. Elaborations of context in the literature

\begin{tabular}{|c|c|c|}
\hline Authors & Viewpoint & Elaborations of context \\
\hline Bradley and Dunlop [14] & $\begin{array}{l}\text { Context-aware } \\
\text { computing }\end{array}$ & $\begin{array}{l}\text { Task context, physical context, social context, } \\
\text { temporal context, cognitive context }\end{array}$ \\
\hline Forlizzi and Ford [6] & User experience & Social, cultural and organizational factors \\
\hline $\begin{array}{l}\text { Hassenzahl and Tractinsky } \\
\text { [7] }\end{array}$ & User experience & $\begin{array}{l}\text { Organizational setting, social setting, } \\
\text { meaningfulness of activity, voluntariness of } \\
\text { use }\end{array}$ \\
\hline Kankainen [8] & User experience & People, places and things surrounding user \\
\hline Lee et al. [21] & Consumer & $\begin{array}{l}\text { Personal (emotion, time, movement), } \\
\text { environmental (physical, social) }\end{array}$ \\
\hline Roto [17] & User experience & $\begin{array}{l}\text { Physical context, social context, temporal } \\
\text { context, task context }\end{array}$ \\
\hline Turel [22] & Mobile work & $\begin{array}{l}\text { Users, time, physical environment (incl. } \\
\text { technology and organization), motivations, } \\
\text { tasks }\end{array}$ \\
\hline $\begin{array}{l}\text { Wiberg and Ljungberg } \\
{[18]}\end{array}$ & Mobile work & Time, place, tasks \\
\hline Zheng and Yuan [4] & Mobile work & $\begin{array}{l}\text { Mobile context, mobile workers, mobile } \\
\text { technologies, mobile tasks }\end{array}$ \\
\hline
\end{tabular}

experience. Therefore we separate the characteristics of the user and system from the context. We also follow the currently proposed definition in ISO standardization [23], which defines user experience as "a person's perceptions and responses that result from the use or anticipated use of a product, system or service." Contextual factors may significantly contribute to the user's perceptions, preferences, behaviors, accomplishments and even emotional responses to using a mobile system or service.

Table 1 summarizes the previously discussed elaborations of context also from user experience and context-aware computing. We can see that definitions of context in different fields have similar components, especially those related to time and place. However, tasks as a contextual component are more strongly emphasized in the mobile work context. Moreover, social context is included in the user experience literature as well as that of context-aware computing, whereas it is missing from the frameworks of context in mobile work related literature. In the case of mobile work, technologies are also mentioned as a part of the context.

User experience has received considerable attention in consumer products and services research. However, there is a lack of empirical research on user experience when using mobile systems for mobile work. The aim of this paper is to contribute to the body of knowledge on factors affecting user experience in mobile work by focusing specifically on the contextual factors. The findings were categorized to form a framework for general dimensions of context in mobile work. Such frameworks have the benefit of making designers, developers as well as user experience experts aware of, and more easily able to identify and evaluate, the contextual factors affecting user experience.

\section{Research Methods}

The focus of this paper is to explore contextual factors affecting user experience in mobile work and how they can be categorized. A multiple case study approach was 
chosen as the research strategy [24] in order to gain more generalizable results. Three cases were studied separately between 2006 and 2008 in Finland, of safety observation at construction sites, passenger transportation, and mobile news journalism (see for example [25], [26]). The cases reported here are a part of two larger research projects.

We used two sources for qualitative data in the safety observation and mobile news journalism case studies, namely observations and semi-structured interviews. By observation we were able to study what kind of contextual factors existed in real usage situations and to gain an understanding of how context affects the user experience. Because in the case of passenger transportation the nature of their work meant the taxi drivers could not be observed, focus groups were arranged instead. Semi-structured interviews were conducted to complete the results of the observations and to gain a deeper understanding of the factors affecting user experience. Notes were written during the observations, while the interviews and focus group discussions were recorded and transcribed.

Each case study was first analyzed separately using content analysis and applying both data triangulation and investigator triangulation. The transcribed observation notes and interviews were first read through to form a general understanding of the data in relation to contextual factors. Inductive reasoning was used in giving descriptive labels and assigning them to lines, sentences or paragraphs [27]. These labels were then grouped to higher level categories. We used cross-case analysis [24] and earlier frameworks of context from ubiquitous computing, user experience, and mobile work related literature to form the main dimensions of context from the categories.

\subsection{Case Study A: Safety Observation at Construction Sites}

At construction sites, we focused on the safety observation process known as TRmeasurement [28]. The process is carried out weekly by the industrial safety delegate and the site supervisor on Finnish construction sites and is aimed at reducing the number of industrial accidents.

Two researchers observed the construction workers for two hours at three different construction sites. Altogether there were six participants aged 25 - 60 years old in three observations. They had used the mobile service from between five to 12 months. At the time of the study, they used the mobile service via their mobile phones (Nokia 6630). After the observations, the participants were interviewed for background information and to go over the observation notes.

\subsection{Case Study B: Passenger Transportation}

In this case study we focused on the work of taxi drivers, where mobile systems play a crucial role in major work tasks such as accepting incoming requests, searching for locations on the map and communicating with dispatch and with other taxis. Installed in the taxis were mobile systems including General Packet Radio System (GPRS) and a touch screen, along with other devices such as a taximeter and an additional touchpad for operating the system. 
Two two-hour long focus groups were arranged with taxi drivers. The first group's five participants (one woman, four men) had an average of 20 years driving experience. The second focus group had four participants (all men) whose taxi driving experience varied from 1.5 to 10 years. The focus groups covered questions related to mobile work tasks, and the benefits and usability of the mobile system, as well as possible problems faced while using it.

\subsection{Case Study C: Mobile News Journalism}

In this case study, ten graduate students of journalism and nine graduate students of visual journalism published an online blog of university events as part of a university course project. Uploading to the blog was done wirelessly directly from the proximity of the reported events. Students used the mobile phone based system for capturing multimedia items, and creating news stories with text and multimedia. The main parts of the mobile journalism system were a mobile multimedia phone (Nokia N82) for photo and video capture, a wireless Bluetooth keyboard (Nokia SU-8W) for writing text, and a research prototype of a mobile software application developed for mobile news creation and submission. A publishing schedule was given by the producer of the publication, replicating the working process of an editorial staff in a newspaper organization.

Three researchers observed eight participants using the mobile system during the first project day, some 24 hours of observations of the mobile work context. Five participants were interviewed before they used the system so as to gather background information, for example, on their earlier experiences of using mobile phones in journalism. Eleven participants were interviewed after the project day to gather information on their experiences including context related aspects. Additional observations of three journalist-photographer pairs and four interviews were made on a second project day a month later.

\section{Results}

In this section we present the results of each case study. First, we characterize the mobile work in each case, as well as the work community in general. We then describe the contextual factors that were emphasized in the cases.

\subsection{Case Study A: Contextual Findings in Safety Observation}

Work at construction sites is traditionally mobile; workers move in and out of the building under construction. The safety observation is also mobile as an industrial safety delegate and a site supervisor walk through the site. The industrial safety delegate makes his safety related findings during the safety observation round and the accompanying supervisor documents them, either traditionally by filling out a specific paper form, or by using a dedicated mobile service developed for this purpose. Photos, complementing the written descriptions of the safety issues, are taken either with the mobile phone or with a separate digital camera. The results of the safety observation round are presented to contractors at a weekly site meeting. 
The construction sites of course vary according to the specific building under construction, the area of the site, the number of workers on the site at any time, and the overall progress of the project. The progress of the construction affects how long the observation round takes and the volume of the findings. In other words, when the construction is at an early stage, the observation round takes about an hour, and there are less than 100 findings; at a later stage, the round can take about two hours and may have up to 500 findings.

Based on our findings with construction workers, infrastructural factors such as functionality of the network connections and the capacity of the mobile device were highlighted. If the building has floors below ground level, such as a cellar, the network connection may be limited or even unavailable at times. However, since the mobile service used for the safety observation sent data to the server in real time, unavailable or cut network connections got the service stuck and the data was not uploaded. In the worst case, the user had to reboot the mobile device and all the gathered data was lost. In that case, the user had two choices in continuing the safety observation: either they tried to remember all the findings already made, or they started again. This took extra time and the user became frustrated. In addition, the risk of making errors increases when the user has to remember all the findings.

Another infrastructural issue highlighted was the capacity of the mobile device due to the working situation. When the observation round takes approximately two hours, the mobile phone battery must be fully charged before the round begins. Environmental factors, such as cold and humidity, were also a factor on construction sites, since although winter weather did not complicate a safety observation round conducted with pen and paper, it did complicate the use of the mobile service. For example, entering data with gloves on is difficult. To quote one user: "The less data is required to be entered when using the mobile service, the better". One of the users had cut the thumb off his gloves to better use the mobile service in winter time. Humidity in contrast, complicated observation rounds conducted with pen and paper, but not with a mobile service, since rain makes paper documentation difficult to write and read, whereas the mobile device was easily placed in a pocket.

\subsection{Case Study B: Contextual Findings in Passenger Transportation}

Taxi drivers' main task is to drive customers from one place to another throughout the day and night, a very customer-orientated service. They accept incoming requests and search for locations on the map with their mobile system. Taxi drivers work in the middle of the traffic with their peak hours being nights and weekends, whereas during the week and the daytime it is quieter. In Finland the taxi owners usually hire one or more drivers. Both the owners and the hired drivers drive the cars, so the users of the mobile system in any given car may be very different. There are, for example, older drivers that have driven taxis for years, and have used older technologies for their work tasks. Younger drivers are usually familiar with computers and new technology and are more at ease using new systems.

We found social factors to be important for taxi drivers. Taxi drivers see each other, for example, when they are waiting for possible customers at a railway station, or when they arrange to have a coffee break together. They also communicate through their mobile system by sending text messages to each other. However, due to the lack 
of support for more private channels between the members of the work community, some of the participants find this communication disturbing. Moreover, unnecessary messaging was also seen to affect driving safety. In addition to messaging, drivers can also follow where their colleagues are through the mobile system, and in this way they can meet each other when they have a break.

Because taxi drivers' work has long traditions, they also have a strong culture among their work community. In related cultural traditions and respect for customers, one taxi driver gave the example that they are supposed to "get out of their car, open the door for customers, and talk to them". According to the interviews, this is more important to them than knowing where a specific street is located. They value their customers and they have also been guided to minimize the use of the mobile system when customers are in the taxi. One driver said: "Prodding at the touch screen draws too much of the customer's attention", and customers may think that the driver is not interested in them. Instead of using the touch screen, many drivers use their mobile system via a touchpad located between the two front seats under the driver's hand, which is therefore less visible and less noticeable to the customers.

Taxi drivers are also proud of their professionalism. As one taxi driver said: "The system cannot guide us by giving, for example, information about the travel time or travelling in general" (for example, how long it takes to drive the customer to the destination). Accordingly, they do not want the mobile system to guide them too much, because they think they know which way to drive better than the system does.

According to our findings, environmental factors were highlighted in taxi drivers' work. Sunshine, for example, makes the work of taxi drivers difficult at times. As one taxi driver stated: "If the sun is shining low and you have a light colored shirt, the shirt reflects the sunshine on the screen." On the other hand, at nights or in the dark the brightness of the screen disturbs the driver if they do not use a screen saver. However, not all taxi drivers were familiar with the screen saver and therefore not all used it. Winter too, makes the taxi drivers' mobile system difficult to use as coldness causes it to boot up very slowly and it takes time to start the work.

Another important contextual factor related to system usage in the taxi drivers work was safety. As one taxi driver said: "Every additional button press is a safety risk". If taxi drivers are required to take their eyes off the road when they use their mobile system while driving, the safety risk increases. Moreover, too small a font size also affects safety, because users have to narrow their eyes to read the text in the display.

\subsection{Case Study C: Contextual Findings in Mobile News Journalism}

The work of news journalists and photographers is highly mobile by nature. In the field, an essential part of the work is to gather the material needed for reporting a newsworthy event. Traditionally, a news journalist uses a pen and a notebook for taking notes and occasionally uses a voice recorder for capturing interviews. On the other hand, a news photographer carries a digital camera and lenses in a camera bag and occasionally a digital camcorder for capturing news clips for the on-line version of the paper. Usually journalists and photographers return to the newsroom to write the story or to select and process the captured photos or videos on desktop computers. However, the work of news journalists and news photographers is changing, due to 
the increasing speed of news publishing, where Internet publishing may require instant reporting and submission of the material from the news scene. Therefore using mobile multimedia phones and services is of interest in this area also.

The work in a news organization is characterized by a fast pace, unexpected events and ever-changing plans. To manage the work of the editorial staff and publishing, publication schedules are drawn up and work is tied to deadlines to allow the timely printing of the newspaper. The pace of the mobile work varies from slow to hurried, covering phases from idle waiting to the moments of rushed work when the deadline is drawing near or when one needs to hurry in submitting time-critical material to an on-line publication. In on-line and mobile news "the deadline is now" as one of the interviewees stated.

In journalism the mobile system, in this case the mobile phone, the wireless keyboard and the mobile journalism application, is primarily a means to achieve a higherlevel goal, like rapidly reporting news to the on-line publication. The mobile system, service and the related infrastructure should therefore support the achievement of these goals. Based on their usage experiences participants emphasized the need for reliable and high performance in the submission of the material. Problems encountered in the study, such as upload times that took over an hour or were interrupted, were partly due to insufficient throughput in submission and in the worst cases prevented the participants carrying out their next assignment or capturing newsworthy material. In addition, we found the editorial process as well as the publishing system to affect the user experience of the journalists and photographers. These need to compensate for the limitations of the mobile system, such as the spelling errors due to writing text with the mobile system.

The reactions of external persons in various forms were important for the users and how they felt about using the system. In their field work, both journalists and photographers work among other people, including their audience and occasionally colleagues from other news organizations. Journalists and photographers are in direct contact with their interviewees, or those they capture in photos and video clips. Participants felt that the mobile system was less visible to others in multimedia capture due its everyday like character and therefore they stated that in certain situations they could more easily fit into the crowd. On the other hand, using a mobile phone made some participants feel that they had lost a symbol of their profession: a large and visible camera. Most of the participants also mentioned that due to the familiarity of the mobile phone, their interviewees were more relaxed when they were photographed with the mobile phone than when they are photographed with a camera.

The locations the participants worked at varied from quiet spaces, like the library or the offices of the university staff being interviewed, to noisy hallways and canteens. To work with the material they had gathered both journalists and photographers typically looked for a nearby public space with chairs, sofas or preferably with tables, like cafes. One journalist described this: "Although you can carry the system to any place, you still need the space and time to work." The public spaces chosen were often crowded and noisy with interruptions and disturbances from people talking and passing by. In addition, journalists' working positions while writing were dictated by the environment. Journalists had trouble in placing their needed items, such as mobile phone, foldable wireless keyboard and traditional notebook, into a stable position on their laps if no table was available. The keyboard had no locking mechanism and 


\section{Task context}

- Interaction when using the system

- The entity and goal of the tasks and work

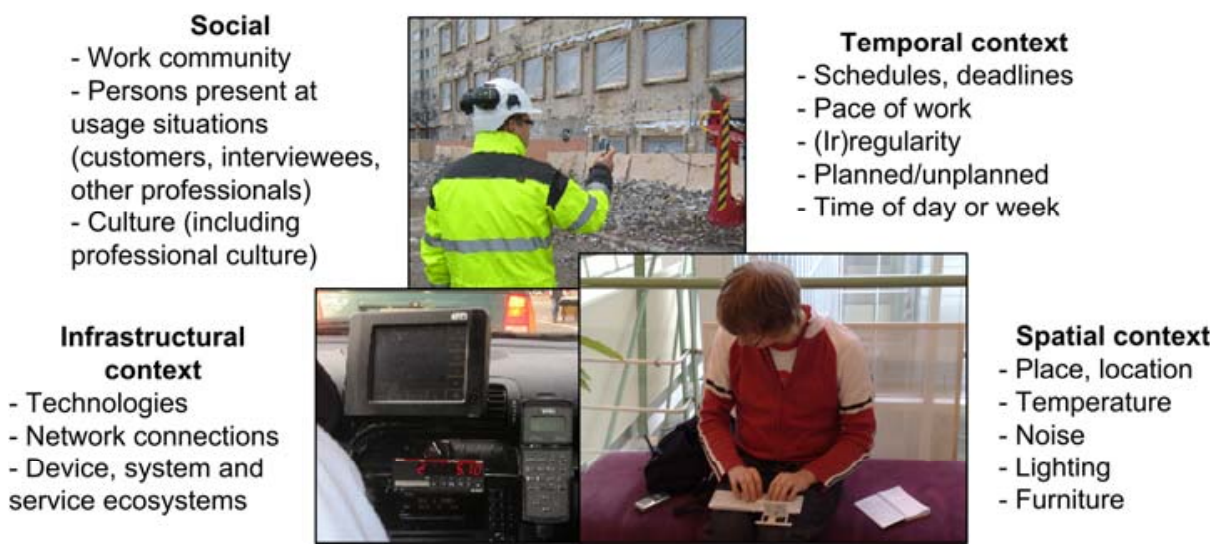

Fig. 1. Contextual factors affecting user experience in mobile work

therefore it started to fold easily while writing. There was also no mechanism for fastening the phone to the keyboard for this type of usage situations (see also Figure 1).

The environmental conditions emphasized by the participants were related to the temperature, lighting and ambient noise when using the mobile system. Photographers commented especially on lighting as an important element for capturing stills and video clips, as if it is too dim or too bright the quality of the captured photos and videos suffers due to the technological limitations of the current mobile phone - or it may not even be possible to capture multimedia material with sufficient quality for publishing. Photographers also emphasized the significance of relatively low ambient noise level for capturing video clips due to the limitations of the microphone. The handling of the mobile system in freezing weather was mentioned to be clumsy with cold fingers and it is not possible to wear gloves when working with it. In addition the battery life was mentioned as being shorter in freezing weather.

\section{Discussion}

In the previous section, we described our case study findings regarding the contextual factors affecting user experience. In this section, we discuss the results and categorize the findings under five dimensions of context relevant in mobile work. In addition, we discuss design implications arising from the findings.

We categorized our findings of the contextual factors affecting user experience in mobile work under five main dimensions, namely 1) social, 2) spatial, 3) temporal, 4) infrastructural, and 5) task context. These five dimensions are illustrated in Figure 1 with a summary of the findings from the three case studies. The presented framework, with its five dimensions (Fig. 1), elaborates upon the approaches in earlier frameworks of context (see Table 1). Compared to these earlier frameworks, two new dimensions are brought in, namely the social and infrastructural contexts. As discussed 
in Section 2, social context is highlighted in user experience frameworks [6], [7] and in context-aware computing [14]. Forlizzi et al. [6] as well as Hassenzahl et al. [7] also mention organizational and cultural factors, which we find to not be separate dimensions of context, but rather to be related to and affecting in the other dimensions of context. Infrastructural context has not been part of the earlier frameworks, although there are references to technology as being part of the context. In the following section we discuss the dimensions of the framework in more detail.

Social context. We found that the presence and reactions of external persons affected both the usage and user experience of the mobile systems. These external persons involved were either in direct contact with the user or indirectly present at the work situation. In our cases the persons who were directly involved with the users in usage situations were taxi passengers, interviewees and persons of whom photos and video clips were captured. Moreover, indirectly present were, for example, construction workers, colleagues or bystanders when reporting news in the field situations. For example, taxi drivers limited the usage of their mobile system when customers were present and preferred to use a conveniently placed touchpad, which drew less attention from the customer. In the case of journalism the participants found that their interviewees were more at ease when they were photographed with a mobile multimedia phone. We found also, that the work community and unofficial mobile communication with colleagues was important, especially in the case of taxi drivers. This also supports the earlier studies of the importance of the need for social communication in mobile work [9] [18]. Taxi drivers communicated with their colleagues through the mobile system by text messages, even though the system was not initially designed for social communication. Moreover, the professional and organizational cultures affect the values and norms of the professional community.

Spatial context. This refers not only to the location where the mobile system is used, but also to the environmental conditions and circumstances, such as available furniture, affecting the work situation and therefore the user experience. Environmental issues, such as temperature, noise, and light affect the use of mobile systems. The effects of cold upon the use and performance of the mobile systems were mentioned in all cases. When capturing multimedia material, lighting and sound conditions especially have an effect on the quality of the captured material. This was particularly emphasized by the news photographers, for whom the quality of the captured multimedia material is very important.

Temporal context. Temporal factors are related not only to the absolute time of day, week or year, but also to schedules and deadlines as well as the pace and regularity of the work. In the case of news journalism, the organization sets schedules and strict deadlines for the news reporting. The pace of the work can also vary due to, for example, external reasons not controllable by the user, like an interviewee being late for the arranged meeting. Plans and schedules may suddenly be changed and cause extreme moments of rushing to accomplish the new assignment. For the taxi drivers the time of day or week affects the pace of the work, nights and weekends being busier for them; whereas the safety observation rounds at construction sites are done regularly on a weekly basis. 
Infrastructural context. The infrastructural factors, especially the functionality of the network connection was important in safety observation and in mobile news journalism. Unavailability, unreliability or other performance related problems of the network make the users frustrated and unsatisfied. Problems in network connections or throughput of the devices may force the users to redo their work tasks or prevent the users of accomplishing further tasks. Further examples of infrastructural context are carrier related costs and in some countries legal circumstances which regulate the use of the mobile system or service and therefore affect the user experience. In the case of mobile news journalism there exist also other systems and processes, including the editorial system and the editorial process, which affect the user experience of the mobile worker. The entire ecosystem of used mobile devices, systems, and services as well as related other systems and work processes could therefore be seen as part of the infrastructural context.

Task context. The task or set of tasks that users carry out with their mobile systems are often only part of higher level goals they have in their work [17]. In the case of news journalism the main tasks for a journalist that are designed to be accomplished using the mobile system are to capture photos or video clips, write the text for an article, add the multimedia items into it and then submit it to editorial. However, the actual goals in reporting news are related to the content and meaningfulness of the news, photos and videos to the audience as well as to the journalistic quality, like errorfreeness, of the published material. This type of goal cannot be accomplished by any system alone, rather the user is in the key role - quoting the words of a participant of a mobile news journalism study - of "using brains" as well as the entire work process. Therefore, understanding both the tasks and the higher level goals is important in designing mobile systems that support the mobile work tasks. However, understanding the diversity of higher level goals especially in non-routine, creative work also simultaneously explains why mobile systems sometimes cannot be designed to support all the goals of their users. This is especially the case when both professional goals and personal ambitions are present.

Implications for design. In the light of the presented contextual dimensions and findings from the study, we present implications for design when developing mobile systems for work purposes. First, regarding the social dimension of context, the mobile systems should be acceptable both for the actual users and also for other people around them. Moreover, results indicate that social communication is important for mobile workers, and something that could be supported by providing private channels for communication. Second, the total attention required to operate the mobile system should be minimized so as to not only maintain the safety of the mobile workers but also of others. Third, mobile systems should support working in different temporal situations allowing flexible and reliable use, especially when in a hurry or when several tasks need to be performed simultaneously. Fourth, optimizing the mobile system and service for maximum throughput in data transmission is of essential importance. Fifth, the real usage environments and situations should be studied, to ensure that the developed systems and services are operable in them. For example, especially in case of mobile workers, users often move during the task or data transmission and therefore the used network connection may not be available at all times. Moreover, due to the work in the mobile field conditions, the drain of the mobile system should be 
minimized so as to extend the device's battery life. Sixth, designers should identify and define the environmental circumstances in which the mobile services are intended to be used. Spatial factors, such as cold and lighting conditions, can be managed, thus allowing the users to control the characteristics of the user interface and to personalize them. Things sometimes taken for granted when writing with mobile systems, like tables or other furniture, are not always available in usage situations.

The dimensions of context presented based on the cross-case analysis of the results are not the only way to categorize the contextual factors affecting user experience. However, we found the five dimensions capture our findings well and the presented dimensions can be used when analyzing and defining the contextual factors in the mobile system and service development. With the help of the framework, for example design heuristics for designing successful mobile services for mobile work and questionnaires for measuring user experiences can be prepared. Although three case studies were used in the analysis, more studies are needed to gain an insight into the similarities and differences between different fields of work as well as defining a more comprehensive list of factors within the dimensions of context. In addition, different cultural and ethical issues may affect the findings and therefore similar studies in different countries would bring interesting new insights regarding the contextual factors. Due to the relatively small number of participants in the cases, the findings can be seen as examples, but they do serve well in this purpose, although especially in the case of the mobile news journalism a further study with professionals working for newspapers is needed. We believe that the reported findings from these three different types of mobile work help in understanding the diversity of contextual factors affecting the user experience in mobile work when using mobile systems for work related tasks. Further studies are needed to verify the applicability of the framework for identifying the contextual factors which affect user experience when designing and evaluating mobile systems and services.

\section{Conclusions}

To explore the nature of mobile work and the contextual factors affecting user experience in different areas of mobile work, we conducted three case studies with construction workers, taxi drivers, and mobile news journalists and photographers. We described the contextual factors that were emphasized in each case study, with the presented results giving examples of the variety of contextual factors affecting user experience. We categorized the findings under five dimensions of context, which were found to affect user experience in mobile work. These five dimensions are 1) social, 2) spatial, 3) temporal, 4) infrastructural, and 5) and task context; they elaborate earlier frameworks for context, and also emphasize factors related to the social and infrastructural dimensions.

Understanding the contextual factors affecting user experience is important in designing and evaluating mobile systems and services. The five dimensions of context presented here can be utilized as a general framework when identifying more specific contextual factors as well as when evaluating the user experience of mobile systems and services. Further empirical research on context would increase the knowledge on similarities and differences in the contextual factors affecting user experience and 
on the applicability of the framework and its dimensions also in other fields than mobile work.

Acknowledgments. We thank our colleagues for their contribution in this work. The research on safety observation and passenger transportation were part of the project MOMENTO, funded by Tekes (the Finnish Funding Agency for Technology and Innovation). The research on mobile news journalism was part of the PALTI project (2007-2009), funded by the Ministry of Education, Finland.

\section{References}

1. Christopoulou, E.: Context as a Necessity in Mobile Applications. In: Lumsden, J. (ed.) Handbook of Research on User Interface Design and Evaluation for Mobile Technology, IGI Global, pp. 187-204 (2008)

2. Kakihara, M., Sørensen, C., Wiberg, M.: Fluid Interaction in Mobile Work Practices, Tokyo Mobile Roundtable, Tokyo, Japan (May 2002)

3. York, J., Pendharkar, P.C.: Human-computer Interaction Issues for Mobile Computing in a Variable Work Context. Int. J. Human-Computer Studies 60(5-6), 771-797 (2004)

4. Zheng, W., Yuan, Y.: Identifying the Differences Between Stationary Office Support and Mobile Work Support: a Conceptual Framework. Int. J. Mob. Commun. 5(1), 107-122 (2007)

5. Reddy, M.C., McDonald, D.W., Pratt, W., Shabot, M.M.: Technology, Work, and Information Flows: Lessons from the Implementation of a Wireless Alert Pager System. Journal of Biomedical Informatics 38(3), 229-238 (2005)

6. Forlizzi, J., Ford, S.: The Building Blocks of Experience: An Early Framework for Interaction Designers. In: DIS 2000, Brooklyn, New York, pp. 419-423 (2000)

7. Hassenzahl, M., Tractinsky, N.: User experience - a Research Agenda. Behaviour and Information Technology 25(2), 91-97 (2006)

8. Kankainen, A.: UCPCD: User-centered Product Concept Design. In: Proc. DUX 2003, pp. 1-13. ACM Press, New York (2003)

9. Nilsson, M., Hertzum, M.: Negotiated Rhythms of Mobile Work: Time, Place, and Work Schedules. In: 2005 international ACM SIGGROUP Conference on Supporting Group Work. GROUP 2005, pp. 148-157. ACM, New York (2005)

10. Pascoe, J., Ryan, N., Morse, D.: Using While Moving: HCI Issues in Fieldwork Environments. ACM Transactions on Computer-Human Interaction 7(3), 417-437 (2000)

11. Sawyer, S., Tapia, A.: The Sociotechnical Nature of Mobile Computing Work: Evidence from a Study of Policing in the United States. International Journal of Technology and Human Interaction 1(3), 1-14 (2005)

12. Hickey, S., Rosa, C., Isomursu, M.: Evaluating the Use of an Audio-video Mobile Phone for Web Magazine Reporters. In: Int. Conference on Mobile Technology, Applications, and Systems 2007, pp. 511-514. ACM Press, New York (2007)

13. Chalmers, M.: A Historical View of Context. Computer Supported Cooperative Work 13, 223-247 (2004)

14. Bradley, N.A., Dunlop, M.D.: Toward a Multidisciplinary Model of Context to Support Context-Aware Computing. Human-Computer Interaction 20, 403-436 (2005)

15. Dey, A.K.: Understanding and Using Context. Personal and Ubiquitous Computing 5, 4-7 (2001) 
16. Dourish, P.: What We Talk about When We Talk about Context. Personal Ubiquitous Computing 8, 19-30 (2004)

17. Roto, V.: Web Browsing on Mobile Phones - Characteristics of User Experience. PhD thesis, Helsinki University of Technology, Finland (2006)

18. Wiberg, M., Ljungberg, F.: Exploring the Vision of "anytime, anywhere" in the Context of Mobile Work. In: Malhotra, Y. (ed.) Knowledge Management and Virtual Organizations, pp. 112-128. Idea Group Publishing (1999)

19. ISO 13407:1999. Human-centred Design Processes for Interactive Systems

20. Kim, H., Kim, J., Lee, Y., Chae, M., Choi, Y.: An Empirical Study of the Use Contexts and Usability Problems in Mobile Internet. In: 35th Annual Hawaii International Conference on System Sciences (2002)

21. Lee, I., Kim, J., Kim, J.: Use Contexts for the Mobile Internet: A Longitudinal Study Monitoring Actual Use of Mobile Internet Services. Int. J. Human-Computer Interaction 18(3), 269-292 (2005)

22. Turel, O.: Contextual Effects on the Usability Dimensions of Mobile Value-added Services: a Conceptual Framework. Int. J. Mobile Communications 4(3), 309-332 (2006)

23. ISO DIS 9241-210:2008. Ergonomics of human system interaction - Part 210: Humancentred design for interactive systems (formerly known as 13407). International Standardization Organization (ISO). Switzerland. Enquiry stage 40.20 (2008)

24. Yin, R.K.: Case Study Research: Design and Methods, 3rd edn. Sage Publications, Inc., Thousand Oaks (2003)

25. Väätäjä, H., Männistö, A., Vainio, T., Jokela, T.: Understanding User Experience to Support Learning for Mobile Journalist's Work. In: Guy, R. (ed.) The Evolution of Mobile Teaching and Learning, pp. 177-210. Informing Science Press, USA (2009)

26. Wigelius, H., Aula, A., Markova, M.: Modeling Tool for Designing Usable Mobile Services. In: Tiainen, T., Isomäki, H., Korpela, M., Mursu, A., Paakki, M.-K., Pekkola, S. (eds.) Proc. of 30th Information Systems Research Seminar in Scandinavia, IRIS30, Tampere, Finland, August 11-14 (2007); Dep. of Comp. Sciences, University of Tampere, Finland, Series of Publications: D - Net Publications D-2007-9, 1330 pages (September 2007), http: / /www.cs.uta.fi/reports/dsarja/

27. Miles, M.B., Huberman, A.M.: Qualitative Data Analysis: An Expanded Sourcebook, 2nd edn. Sage Publications, USA (1994)

28. Laitinen, H., Marjamäki, M., Päivärinta, K.: The Validity of the TR Safety Observation Method on Building Construction. Accident Analysis and Prevention 51(5), 463-472 (1999) 